\title{
A questão da identidade em perspectiva pragmática*
}

Daniel do Nascimento e Silva

Universidade Estadual de Campinas - UNICAMP

University of California, Berkeley

O lugar da identidade é um lugar sem lugar; em outras palavras, o lugar da identidade está no horizonte do impossível.

Élida Ferreira

RESUMO: Este trabalho apresenta uma reflexão sobre a questão da identidade a partir de uma perspectiva da pragmática lingüística. Apresentar uma perspectiva pragmática é, de partida, uma empreitada interdisciplinar, uma vez que este é um campo híbrido que surge na filosofia e, por assim dizer, dissemina-se na lingüística e na seara maior dos estudos da linguagem. Trata-se, então, de delinear uma visão performativa da identidade, esse construto teórico que tem ocupado um lugar central na agenda das ciências humanas e da vida social contemporânea.

PALAVRAS-CHAVE: identidade; atos de fala; pragmática; modernidade tardia.

ABSTRACT: The present paper aims at discussing the question of identity from a pragmatic perspective. Needless to say, adopting a "pragmatic perspective" entails adopting an interdisciplinary approach, once pragmatics is a hybrid field, first appearing within Philosophy, then disseminating into Linguistics and into the major realm of language studies. The paper deals, therefore, with a certain delineation of a performative view of identity, such theoretical construct that occupies a central place within the agenda of both human sciences and the contemporary social life.

KEY-WORDS: identity; speech acts; pragmatics; late modernity.

* Este trabalho faz parte de pesquisa de doutorado sobre a questão da identidade ora em andamento na Universidade Estadual de Campinas e na University of California at Berkeley. Gostaria de agradecer aos meus orientadores, Kanavillil Rajagopalan (Unicamp) e Charles Briggs (UC Berkeley), por toda a interlocução. Agradeço também à Fapesp (Proc. 05/59907-9) e à Capes (BEX 1466/07-0) pelo apoio financeiro, sem o qual a realização deste trabalho seria impossível. Finalmente, agradeço as valiosas críticas e sugestôes do(a)s três pareceristas anônimo(a)s da Revista Brasileira de Lingüística Aplicada. As eventuais falhas são de minha responsabilidade. 


\section{Introdução}

Escolher esta epígrafe para o dizer de identidade de que agora me aproprio e, assim, com a autora, reafirmá-la, pode soar como um desânimo, talvez um delírio, para quem deseja tratar positivamente do conceito de identidade. Afinal, onde situar um conceito que não tem lugar? Como posso me apropriar de algo que se delineia no horizonte do impossível? Como falar de algo que nos escapa? Seria o caso de tratar do ininteligível? É essa uma tarefa cética? A epígrafe pode ser lida, por outro lado, como indício da crise por que passam não apenas as identidades, mas também o próprio conceito de identidade. Trata-se de um conceito que designa algo que não é fixo, que está em constante transformação, dadas as fronteiras cada vez menos delimitadas da nação, da religião, da língua, da etnia etc., na velocidade da globalização; e ele mesmo não é, como diz a autora, "nunca fechado, pronto e acabado"; ao contrário, "está sempre em construção" (FERREIRA, 2002, p. 11). Objeto de preocupação interdisciplinar, a identidade inquieta não apenas os estudiosos da linguagem: é ele, no dizer do sociólogo Stuart Hall, um conceito "demasiadamente complexo, muito pouco desenvolvido e muito pouco compreendido na ciência social contemporânea" (2002, p. 8). A idéia de identidade, conforme delineada acima, dissemina "incertezas e angústias", tendo em vista que pode gerar "desdobramentos pouco imagináveis até pouco tempo atrás" (RAJAGOPALAN, 2003, p. 1). Falar da identidade é uma ousadia. É, ao mesmo tempo, um risco que, se não assumido, certamente não permitirá o escrutínio desse lugar impossível.

Tendo em vista o risco e a ousadia implicados nesse dizer, este artigo se debruça sobre a questão da identidade, a fim de problematizá-la à luz das discussões atuais do campo da Pragmática Lingüística. A proposta aqui é delinear uma visão "performativa da identidade". Essa expressão inspira-se na "visão performativa da linguagem", tal como proposta por Rajagopalan (2000) e Ottoni (1998) em suas análises da concepção de linguagem de J. L. Austin. Uma visão performativa da identidade parte, nesse sentido, de certa interpretação da teoria dos atos de fala e das implicações dessa teoria para a compreensão da questão identitária.

O artigo está dividido em quatro seçôes. A primeira esboça um histórico do conceito de identidade. A segunda discute a natureza reflexiva da modernidade, instituição crucial para a compreensão dos contornos da questão da identidade atualmente. A terceira seção delineia um panorama da pragmática lingüística diante de sua preocupação com as questôes da 
modernidade. Finalmente, a quarta seção apresenta, a partir de uma visão da pragmática como um campo híbrido (de interface da filosofia com os estudos da linguagem), uma interpretação da teoria dos atos de fala que se poderia chamar de "leitura alternativa", à medida que se opõe à "leitura oficial", atribuída, principalmente, a John Searle (1969).

\section{Breve história da questão da identidade}

A questão da identidade é antiga. Remonta ao pensamento de Aristóteles. Foi com o princípio da não-contradição que o problema ganhou formulação lógica. Segundo esse princípio, é impossível que se diga simultaneamente que o mesmo é e não é. Trata-se, segundo Aristóteles, de um dos princípios mais firmes para o conhecimento da essência de todo e qualquer ser, ou seja, de sua identidade. A ênfase aqui não recai na identidade de um sujeito (individual ou social), uma vez que tal categoria inexistia na época, mas na identidade ou essência das coisas (GONDAR, 2002, p. 107).

Essa concepção essencialista teve grande repercussão no modo como a identidade foi teorizada desde então. A equação do problema permaneceu por muito tempo como identidade sendo igual a essência. As (in)variáveis dessa equação eram, naturalmente, a fixidez, a imutabilidade e a estabilidade. $\mathrm{O}$ surgimento do conceito de indivíduo, no início da modernidade, revela a tentativa de compreender o sujeito como tendo um centro, núcleo estável que garantiria, em última instância, sua segurança e totalidade. Indivíduo é aquele cujo cerne é "individido e indivisível" (RAJAGOPALAN, 1998, p. 29), portanto unificado e único. Situam-se aí, por exemplo, o sujeito do Iluminismo, indivíduo soberano, apto à razão e à consciência, dono de uma essência que, embora se desenvolvesse ao longo de seu amadurecimento, permanecia a mesma (HALL, 2003), e o sujeito do cogito cartesiano, cuja capacidade para a razão garantiria sua própria existência. Trata-se de teorias sobre o sujeito que postulam que, quanto mais este for capaz de racionalmente compreender o mundo e a si mesmo, mais será capaz de moldar a história aos seus próprios fins. Afinal, a crença racionalista era de que se libertar de hábitos e preconceitos do passado garantiria a possibilidade de controlar o futuro (GIDDENS, 2003).

Tais concepções de sujeito, que podemos chamar de humanistas, pressupóem a existência de uma pessoa substantiva, "portadora de vários atributos essenciais e não essenciais” (BUTLER, 2003, p. 29). E tais gestos de teorização não se deram sem implicações para a teoria social e para a história 
das idéias. Essas posições revelam, na perspectiva sociológica, um sujeito que assume prioridade ontológica aos vários papéis e funções que lhe garantem viabilidade e significado sociais. E, na filosofia, um sujeito que está "fora" da estrutura definidora de sua condição de sujeito, qual seja a consciência, a capacidade para a linguagem ou a deliberação moral (BUTLER, 2003, p. 37-38). Tem-se aí um sujeito soberano, doador de sentido, independente de certas instâncias, como o inconsciente ou o poder, que venham abalar a segurança de sua identidade, que é, por definição, idêntica a si mesma, contínua ao longo do tempo, unificada e internamente coerente.

Metafísica da substância é uma expressão atribuída à crítica empreendida por Nietzsche ao discurso filosófico que gerou essa noção de pessoa substantiva. Nos termos de Michel Haar (apud BUTLER, 2003), que parte da posição de Nietzsche a respeito da metafísica da substância, diversas ontologias filosóficas caíram na armadilha de que categorias como "ser" e "substância" são promovidas por categorias gramaticais que espelham uma realidade exterior à linguagem. Diz Haar que foi a gramática que motivou a certeza de Descartes de que "eu" é o sujeito de "penso", "enquanto, na verdade, são os pensamentos que vêm a 'mim': no fundo, a fé na gramática simplesmente traduz a vontade de ser a 'causa' dos pensamentos de alguém" (HAAR apud BUTLER, 2003, p. 43). Haar chega a afirmar que conceitos psicológicos como "sujeito", "eu" e "indivíduo" são falsos, uma vez que são produto da ilusão de uma identidade substancial, transformando em "substâncias fictícias unidades que inicialmente só têm realidade lingüística”. Para o filósofo, a desconstrução da metafísica da substância implica, portanto, a desconstrução do sujeito psicológico como coisa substantiva.

Esboçarei, a seguir, uma crítica à visão essencialista de identidade a partir de uma reflexão sobre a modernidade tardia ${ }^{1}$ e sobre a maneira como teóricos da e na modernidade têm tratado temas como a ética, a subjetividade e a alteridade.

\footnotetext{
1 "Modernidade tardia" ou "alta modernidade" são termos que se referem ao estado atual que alcançou a modernidade, essa organização social surgida na Europa a partir do século XVII. Tal estado é marcado pela "radicalização e globalização dos traços básicos da modernidade" (GIDDENS, 2002, p. 221). Neste artigo, também emprego o termo "modernidade", sem qualificá-lo, como sinônimo dos referidos sintagmas.
} 


\section{A questão da modernidade tardia}

$\mathrm{Na}$ teoria social e nos estudos culturais, a questão da identidade tem sido discutida de maneira articulada com a compreensão desse fenômeno multifacetado chamado modernidade. Passemos agora a um exame de como esses campos do saber têm abordado o tema da modernidade e as suas implicações para a compreensão da questão identitária.

A modernidade, esse "fenômeno perturbador e tumultuado", nas palavras de Giddens (2002), é uma ordem pós-tradicional que instaura uma organização tal nas sociedades (e.g. surgimento do estado-nação, distanciamento espaço-tempo, introdução de sistemas abstratos) que as diferencia das feições que assumiram em todos os outros períodos da tradição. A alta modernidade vem provocando não apenas mudanças na natureza e no funcionamento das instituições sociais, mas tem também influenciado diretamente a subjetividade, de modo que questôes como "quem sou eu?", "qual o sentido de minha existência nesse mundo?", "como devo conduzir minha vida?" têm adquirido emergência e premência ainda maiores. Trata-se de questões que têm de ser respondidas não apenas corriqueiramente ao decidirmos como devemos agir, o que comer e como nos vestir, entre outras, mas pressupõem uma interpretação contínua, "no desdobrar temporal da auto-identidade" (ibid., p. 21).

$\mathrm{Na}$ tradição, a atividade social vincula-se a uma repetição. A estrutura para a ação dos indivíduos na tradição não permite muitas alternativas. Embora possam ser verificadas mudanças no interior de uma tradição, isso ocorre sem que haja questionamentos. Os depositários do conhecimento nas tradições são em geral os sábios, os sacerdotes, os feiticeiros - aqueles a quem Giddens chama de guardiōes, que são diferentes dos especialistas. Embora seja evidente o fato de que as tradições estejam cada vez mais enfraquecidas no âmbito da modernidade, perdendo, sucessivamente, a sua capacidade de guiar os seres humanos em suas atividades rotineiras, não se pode afirmar que a modernidade tenha abandonado totalmente a tradição. Na verdade, convivemos atualmente com muitas facetas da tradição, mas o domínio que ela exercia sobre o comportamento do indivíduo está, sem sombra de dúvida, declinando. O que se observa atualmente, nos termos de Giddens, é que a tradição está sendo vivida de maneira cada vez menos tradicional. Diz o autor:

[v]iver a tradição de maneira tradicional significa defender as atividades tradicionais por meio de seu próprio ritual e simbolismo - defender a tradição por meio de suas pretensōes internas à verdade (GIDDENS, 2003, p. 53). 
O senso de identidade, que na tradição é experimentado em termos de posições sociais fixas e estáveis ocupadas pelo indivíduo na sociedade, tem-se tornado cada vez mais reflexivo. Em outras palavras, a identidade torna-se, no contexto da modernidade tardia, um projeto reflexivo do eu. É importante observar que muitas das tradições são invençôes recentes. Ou seja, muitas das tradições com as quais convivemos e que acreditamos existirem "desde sempre" são fabricadas (HOBSBAWN, 1997); nesse sentido, podem ser vistas como fazendo parte do movimento reflexivo da alta modernidade. Por exemplo, independentemente da continuidade histórica que se atribua aos judeus ou aos muçulmanos do Oriente Médio, o fato é que a idéia de nacionalismo envolvida nos intensos conflitos entre judeus e palestinos, ocasionados sobretudo em função da luta pelo cunho de um Estado territorial, é uma invenção recente, uma vez que a noção mesma de "Estado territorial do tipo padronizado (...) só veio a tornar-se uma probabilidade séria após a I Guerra” (HOBSBAWN, 1997 , p. 22). A própria idéia de tradição é uma invenção da modernidade “o termo 'tradição', tal como é usado atualmente, é na verdade um produto dos últimos duzentos anos na Europa” (GIDDENS, 2003, p. 49-50). Uma derivação possível desse argumento é que as sociedades tradicionais não precisavam lançar mão desse conceito porque a tradição, o ritual e o costume eram o que constituíam o seu funcionamento: no horizonte de uma sociedade cujo funcionamento segue ipsis literirs o padrão de comportamentos estabelecidos de maneira não-reflexiva, faria pouco sentido teorizar sobre tradição. Parafraseando a personagem Addie Burden, de William Faulkner, para quem "a palavra maternidade foi inventada por alguém que precisava de uma palavra para justificar-se, pois os que têm filhos não se preocupam em arranjar palavra para isso", ou que "a palavra medo foi inventada por quem nunca teve medo; orgulho, por alguém que jamais teve orgulho" (FAULKNER, 1978, p.143), podemos afirmar que o conceito de tradição foi inventado por aqueles que não queriam se identificar com ela. Trata-se de um termo cunhado principalmente em função do interesse iluminista de identificar a tradição com o inverso do ideal do iluminismo, i.e., o dogma e a ignorância.

Giddens (1991) argumenta que a modernidade apresenta descontinuidades que a distinguem fortemente das ordens sociais tradicionais. Uma delas é o intenso "ritmo da mudança" (ibid., p.15) presente nas sociedades modernas. Trata-se de um movimento de mudança extremo, visível não apenas no âmbito da tecnologia, mas também em outras esferas. Uma outra remete ao "escopo da mudança” (id. ibid.), verificável pela dinâmica interconexão entre pessoas, 
serviços, informações etc. nas mais diversas áreas do globo. Uma terceira característica das descontinuidades da modernidade sugeridas pelo autor diz respeito à "natureza intrínseca das instituições modernas" (id. ibid.). O estadonação e a transformação do trabalho assalariado em mercadoria, por exemplo, não têm precedentes em nenhuma forma social tradicional. Outras formas sociais, como as cidades, encontram apenas uma certa continuidade com ordens sociais precedentes - mas a sua organização segue leis e princípios completamente diferentes de suas antecessoras (as cidades pré-modernas, no caso).

$\mathrm{Na}$ esteira das transformaçôes que se verificam nas sociedades contemporâneas, pode-se perceber que noções como sina e destino são substituídas, na modernidade, pela consciência do risco (GIDDENS, 2002). Este é um período em que não se pode esperar por segurança. Se os sistemas abstratos pressupunham uma totalidade, tal como se pode perceber na GU chomskyana, o que se percebe é que, na modernidade, o risco, um certo sentimento de um sujeito na corda bamba, que tem de escolher constantemente, substitui essa pretensão de totalidade. De acordo com Giddens,

quando as reivindicações da razão substituíram as da tradição, elas pareciam oferecer uma sensação de certeza maior do que a que era propiciada pelo dogma anterior. Mas esta idéia parece persuasiva apenas na medida em que não vemos que a reflexividade da modernidade de fato subverte a razão, pelo menos onde a razão é entendida como ganho de conhecimento certo. A modernidade é constituída por e através de conhecimento reflexivamente aplicado, mas a equação entre conhecimento e certeza revelou-se erroneamente interpretada. Estamos em grande parte num mundo que é inteiramente constituído através de conhecimento reflexivamente aplicado, mas onde, ao mesmo tempo, não podemos nunca estar seguros de que qualquer elemento dado deste conhecimento não será revisado (GIDDENS, 1991, p. 46).

Outro elemento constitutivo da alta modernidade é a aplicação do conhecimento nas atividades cotidianas. Dito de outro modo, a modernidade é uma instituição eminentemente reflexiva (GIDDENS, 1991, 1993, 2002). Como vimos, a atividade social e a relação dos seres humanos com a natureza são cada vez mais distanciadas de preceitos estabelecidos pela tradição, sendo (re)vistas principalmente à luz do conhecimento, produzido não apenas pelos sistemas especializados, mas também pelo saber comum.

No contexto de uma ordem pós-tradicional, não apenas a atividade social, mas também o "eu" se torna um projeto reflexivo. Reivindicar uma 
identidade é algo que se estabelece na condução reflexiva e rotineira das atividades: "auto-identidade (...) não é algo simplesmente apresentado, como resultado das continuidades do sistema de ação do indivíduo, mas algo que deve ser criado e sustentado rotineiramente nas atividades reflexivas do indivíduo" (GIDDENS, 2002, p. 54). É sobre uma (fragmentada) biografia que o indivíduo oferece de si mesmo que se sustenta sua identidade. Diz o autor:

[a] auto-identidade não é um traço distintivo, ou mesmo uma pluralidade de traços, possuído pelo indivíduo. É o eu compreendido reflexivamente pela pessoa em termos de sua biografia. (...) A identidade de uma pessoa não se encontra no comportamento nem - por mais importante que seja - nas reações dos outros, mas na capacidade de manter em andamento uma narrativa particular (GIDDENS, 2002, p. 54-56, grifos do autor).

Aventar a possibilidade de a identidade ser constituída a partir da narrativa que o sujeito fornece de si mesmo indica a relação mesma da identidade com a linguagem e com a alteridade. Dito em outras palavras, é contra o pano de fundo da relação de diferença estabelecida com o outro, no palco da linguagem, que se forja certa identidade. Cabe pensar a ação do sujeito, em termos não apenas da reivindicação de certa identidade, mas também de outras atividades, como algo que se dá no horizonte de uma "vida responsável". Encontramos na ética bakhtiniana uma argumentação sobre o ato responsável, i.e., o ato que responde ao outro. Interessa a Bakhtin o caráter responsável de cada ato único e irrepetível. Nos termos de Bakhtin (1993), "ser" é ser responsável - é responder ao outro. Numa crítica evidente à tradição iluminista e a uma visão imanentista da ética, Bakhtin defende que nossos atos responsáveis situam-se para além de certa racionalidade:

$\mathrm{O}$ ato realmente realizado em seu todo indivisível é mais do que racional; ele é responsável. A racionalidade é apenas um momento da responsabilidade, [2-3 palavras ilegíveis] luz que é "como o brilho de uma lâmpada frente ao sol" (Nietzsche).

Toda a filosofia moderna nasceu do racionalismo e está completamente impregnada pelo preconceito do racionalismo (mesmo quando tenta conscientemente livrar-se desse preconceito) de que apenas a lógica é clara e racional, quando, ao contrário, é elementar e cega fora dos limites de uma consciência responsável, exatamente como qualquer ser-em-si é. A claridade e a necessária consistência da lógica, quando separadas do centro unitário e único constituído pela consciência responsável, são 
forças cegas e elementares precisamente por causa da lei inerente à lógica - a lei da necessidade imanente. $\mathrm{O}$ mesmo erro do racionalismo se reflete na contraposição do objetivo como o racional, ao subjetivo, individual, singular, como o irracional e o fortuito (BAKHTIN, 1993, p. 47, ênfase acrescida).

Nossas ações responsáveis são, portanto, as respostas que damos a outrem. Segundo o autor, é na eventicidade única do Ser-evento que, responsavelmente, ou responsivamente, realizamos nossos atos. Imbuídos de história, "pensando teoricamente, contemplando esteticamente e agindo eticamente", não podemos encontrar um álibi para a existência. E existir é algo que se dá de uma vez por todas, "pra valer". Diz Bakhtin: "[e]u existo no mundo da realidade inescapável, e não no mundo da possibilidade contingente" (p.62). Tal como o amante que significa seu sentimento no "eu te amo e assumo todas as conseqüências que isso possa implicar", o sujeito bakhtiniano reconhece que, uma vez existindo, isso é irreversível.

Tratar a identidade como um processo reflexivo, que se estabelece face ao outro e que se constitui na e pela linguagem (Cf. RAJAGOPALAN, 1998), não a isenta, entretanto, de ansiedades e contradições. A alta modernidade é um período que não é imune ao mal-estar. Podemos afirmar que, no diálogo mesmo com a alteridade, a reivindicação de uma identidade não se dá sem o peso da contradição e do conflito. Nos termos de Bauman:

de um lado, ele [o indivíduo] precisa dos outros como do ar que respira, mas, ao mesmo tempo, ele tem medo de desenvolver relacionamentos mais profundos, que o imobilizem num mundo em permanente movimento (apud PALLARES-BURKE, 2003).

A essa altura da discussão que empreendemos sobre a identidade com base na idéia de modernidade tardia, gostaria de fazer uma breve alusão a uma personagem que considero emblemática da visão de sujeito e identidade que discutimos até aqui. Trata-se de G.H., personagem de Clarice Lispector que narra reflexivamente sua própria existência em $A$ Paixão Segundo G.H. Numa narrativa não-linear, fragmentada, epítome da identidade do sujeito da modernidade tardia, Clarice Lispector nos apresenta A Paixão Segundo G.H., um "livro que nada tira de ninguém" (LISPECTOR, 1998, p. 7). A obra, em linhas gerais, consiste no relato de G.H. sobre o caminho que ela mesma percorre na reflexão sobre sua própria humanidade. G.H., mulher de classe média, privilegiada pelo acesso à educação e ao dinheiro, se dá conta, a partir 
de um encontro inesperado, que o que ela é não lhe havia sido dado - ao contrário, consistia em algo que precisava sofregamente ser reivindicado e construído:

[é] difícil perder-se. É tão difícil que provavelmente arrumarei depressa um modo de me achar, mesmo que achar-me seja de novo a mentira de que vivo. Até agora achar-me era ter uma idéia de pessoa e nela me engastar: nessa pessoa organizada eu me encarnava, e nem mesmo sentia o grande esforço de construção que é viver. A idéia que eu fazia de pessoa vinha de minha terceira perna, daquela que me plantava no chão (p.12, ênfase acrescida).

A terceira perna de que fala G.H. pode ser compreendida em termos do conceito de 'segurança ontológica': era essa terceira perna que ancorava G.H., estavelmente, em seu agir. E foi justamente a perda dessa perna "acessória" que lhe impeliu a questionar as bases de sua própria identidade.

Perdi alguma coisa que me era essencial, e que já não me é mais. Não me é necessária, assim como se eu tivesse perdido uma terceira perna que até então me impossibilitava de andar mas que fazia de mim um tripé estável. Essa terceira perna eu perdi. E voltei a ser uma pessoa que nunca fui. Voltei a ter o que nunca tive: apenas as duas pernas. Sei que somente com duas pernas é que posso caminhar. Mas a ausência inútil da terceira me faz falta e me assusta, era ela que fazia de mim uma coisa encontrável por mim mesma, e sem sequer precisar me procurar (p. 11-12).

O encontro epifânico de G.H. pode ser descrito assim. Ao deparar com uma barata num território desconhecido de seu próprio apartamento - o quarto de Janair, empregada doméstica que fora demitida -, G.H. é confrontada com o mal-estar e o desconforto. É esse encontro com a barata que desencadeia uma série de questionamentos, restando-lhe apenas percorrer o caminho das paixões (o que na religião se assemelha à via crucis e, na música, à Paixão Segundo São Mateus, de Bach): "[é] que um mundo todo vivo tem a força de Inferno" (p. 22). Acredito que "paixão", nessa obra, pode ser entendida como uma metáfora da trajetória por que passa o sujeito da modernidade tardia. Ou seja, as inquietações de G.H. não são apenas dilemas e conflitos de alguém que está atormentado, mas também (e principalmente) dilemas e conflitos da identidade do sujeito moderno.

Para G.H., é na relação com o outro que se decide quem se é: "[m]inha pergunta, se havia, não era: "que sou”, mas "entre quais eu sou" (p. 28). A vida 
lhe está doendo e, por isso, G.H. pede a "mão desconhecida" do outro. Pedir a mão do outro, nesse sentido, significa para ela não apenas uma ancoragem, a busca desesperada por uma segurança ontológica, mas também um passo, em meio ao mal-estar, rumo à busca de um sentido para a identidade:

- Ah, não retires de mim a tua mão, eu me prometo que talvez até o fim deste relato impossível talvez eu entenda, talvez pelo caminho do inferno eu chegue a encontrar o que nós precisamos - mas não retires tua mão, mesmo que eu já saiba que encontrar tem que ser pelo caminho daquilo que somos, se eu conseguir não me afundar definitivamente naquilo que somos (p. 73, ênfase acrescida).

De acordo com G.H., aceitar toda a fragmentação provocada pelo encontro com a barata é um ato de coragem, "como a de um sonâmbulo que simplesmente vai" (p.17). Num ritmo que remete à descontinuidade da modernidade em relação à tradição e aos processos nisso envolvidos, a transformação por que passa G.H. obriga-a a abandonar qualquer segurança ou totalidade:

[t]alvez desilusão seja o medo de não pertencer mais a um sistema. No entanto se deveria dizer assim: ele está muito feliz porque finalmente foi desiludido. $\mathrm{O}$ que eu era antes não me era bom. Mas era desse nãobom que eu havia criado um bem futuro. $\mathrm{O}$ medo agora é que meu novo modo não faça sentido? Mas por que não me deixo guiar pelo que for acontecendo? Terei que correr o sagrado risco do acaso. E substituirei o destino pela probabilidade (p.13, ênfase acrescida).

A insegurança, a dúvida, o mal-estar, elementos de que G.H. passa a se dar conta, são acompanhados pela falha, noção que, conforme veremos a seguir, acompanha a ação humana e, nesse sentido, o ato de fala. Mal de que todo ato de fala é herdeiro, nos termos de Austin, a falha (ou mais precisamente, em Austin, a infelicidade), é assim abordada por G.H.:

[e]sse modo de não ser era tão mais agradável, tão mais limpo: pois, sem estar agora sendo irônica, sou uma mulher de espírito. E de corpo espirituoso. À mesa do café eu enquadrava com meu robe branco, meu rosto limpo e bem esculpido, e um corpo simples. De mim irradiavase a espécie de bondade que vem da indulgência pelos próprios prazeres e pelos prazeres dos outros. Eu comia delicadamente o meu, e delicadamente enxugava a boca com o guardanapo. Esse ela, G.H. no couro das valises, era eu; sou eu - ainda? Não. Desde já calculo que 
aquilo que de mais duro minha vaidade terá de enfrentar será o julgamento de mim mesma: terei toda a aparência de quem falhou, e só eu saberei se foi a falha necessária (p. 32, ênfase acrescida).

Aquilo em que G.H. ancorava sua segurança ontológica - o couro de suas valises, por exemplo - parece assumir um novo significado após o encontro com a barata: "[e] sse ela, G.H. no couro das valises, era eu; sou eu ainda? Não". Eis que G.H. depara com o domínio da falta e da falha, um território, como veremos na seção seguinte, em que se assenta o ato de fala. Passemos, agora, a uma discussão em torno do performativo - e, naturalmente, de suas falhas.

\section{Pragmática e modernidade tardia}

Os deslocamentos que o tema da modernidade tardia têm provocado na concepção de identidade, vista agora não mais como categoria estável, garantida a priori, seja pela tradição, pela biologia etc., mas, sim, como construto, algo a ser negociado e reivindicado pelo indivíduo por meio de uma narrativa do eu, portanto na e pela linguagem, são cruciais para a concepção de linguagem, ciência e subjetividade que ocupa a agenda da pragmática lingüística atualmente. É, afinal, o gesto de observar o uso da linguagem ordinária, tendo em vista seu potencial de clarificação de problemas filosóficos de longo alcance, em detrimento de uma abordagem introspectiva que acredite num acesso direto à "essência da realidade", que marca a importância do trabalho dos filósofos da linguagem ordinária, em especial J. L. Austin. A confissão de Austin, a seguir, se observada contra o pano de fundo de um momento da história da filosofia em que se criticam abordagens teóricas ontologizantes, orientadas para um conhecimento que se situa para além do saber comum e do trabalho do sujeito face a esse saber, é bastante significativa:

(...) permitam-me fazer uma observação geral, ou melhor, uma confissão. Muitos de vocês ficarão impacientes com essa abordagem e de algum modo isso é justificável. Vocês dirão: "Por que não ir direto ao ponto? Por que prosseguir com listas de nomes disponíveis na linguagem ordinária, nomes para coisas que têm relação com o dizer, e com fórmulas como "em" e "ao" dizer? Por que não discutir a coisa diretamente nos termos da lingüística e da filosofia? Por que tantos desvios?" Bem, é claro que eu concordo que tudo isso deve ser feito mas eu diria depois, não antes, de observar o que podemos extrair da linguagem ordinária, mesmo que o resultado seja algo óbvio. Caso 
contrário, podemos desconsiderar coisas importantes e ir rápido demais (AUSTIN, 1975, p. 123, ênfase no original) ${ }^{2}$.

Trata-se de uma posição teórico-metodológica que põe em xeque toda uma metafísica interessada em um conhecimento que se situa para além do saber comum de pessoas comuns. A partir desse gesto de dar atenção ao uso que os falantes fazem da linguagem ordinária, no contexto da natureza eminentemente reflexiva da atividade social da modernidade tardia, podemos delinear uma reflexão sobre um sujeito que não é senhor de si, mas alguém que vive na corda bamba, tendo de fazer escolhas continuamente no desdobrar temporal e dialógico de sua ação no mundo. Nesse sentido, podemos insistir que a linguagem é menos um sistema formal do que um palco da ação de sujeitos éticos que performativamente negociam sentido para sua existência.

Perguntas formuladas na esteira dos estudos no campo da pragmática lingüística poderiam ser descritas da seguinte forma: o que acontece por trás para que se diga uma coisa e não outra? que ações podem ser acarretadas se eu disser isso e não aquilo? o que eu sou depende do que eu falo? qual o estatuto do "outro" em meu dizer? palavras ferem? quando digo, constato um estado de coisas ou opero uma realidade?

Central a essas questões está o problema do performativo, o enunciado cuja enunciação já é um fazer. Levantada primeiramente por Austin (1975), a questão do performativo insere-se nas discussões do filósofo inglês sobre os atos de fala e tem ocupado um lugar nada marginal nos estudos que se vêm desenvolvendo no âmbito da pragmática e para além deles. Diversos gestos de interpretação do conceito de "ato de fala" podem ser verificados em trabalhos no campo dos estudos culturais, da antropologia, dos estudos feministas, da psicanálise, entre outros.

O que se percebe nas questões levantadas em tais estudos, respeitada a singularidade de cada abordagem, é que ultrapassam o conceito de comunicação, em sentido estrito, estendendo-se à experiência humana de uma maneira mais geral. Na leitura de Derrida da teoria dos atos de fala, por exemplo, comunicar, nos termos do performativo, é comunicar uma força por impulsão de uma marca (DERRIDA, 1991, p. 363). Acontece que implícitas em toda marca

\footnotetext{
${ }^{2}$ A tradução dos excertos citados dos textos em língua estrangeira foi realizada por mim. Embora haja uma tradução para o português brasileiro desse texto de Austin, realizada por Danilo Marcondes, os excertos aqui citados são traduzidos por mim. Uma crítica à tradução de Marcondes pode ser encontrada em Silva (2005).
} 
estão a ausência (do destinatário e também do emissor) e a iterabilidade ${ }^{3}$. Esse apagamento e essa possibilidade de repetição, para Derrida, podem ser estendidos à totalidade da "experiência", na medida em que esta não se separa da marca, a qual, nesse sentido, funciona na cadeia de sua repetição face à alteridade, na esteira do apagamento e da diferença.

Esta possibilidade estrutural de ser privada do referente ou do significado (portanto da comunicação e do seu contexto) parece-me fazer de qualquer marca, seja ela oral, um grafema em geral, quer dizer, como se viu, a permanência não-presente de uma marca diferencial separada da sua pretensa "produção" ou origem. E estenderei mesmo esta lei a qualquer "experiência" em geral se for adquirido que não existe experiência de pura presença mas apenas cadeias de marcas diferenciais. (p. 359)

Mas não se entenda essa repetição como uma manutenção estável ou fixa do significante. A repetição inscrita na iterabilidade é, na verdade, uma repetição. Nela se delineia o território do outro, que, na sua re-petitio, instaura a novidade, justamente porque "não há incompatibilidade entre a repetição e a novidade do que difere" (DERRIDA, 2004, p. 331). Nos termos de Derrida, o singular "chega", de modo imprevisível, por meio da repetição. Derrida inclusive declara sua paixão pela expressão de uma vez por todas [une fois pour toutes], que revela a natureza singular e irreversível daquilo que só acontece uma vez e, por isso mesmo, não se repete mais. Mas que, ao mesmo tempo, articula-se a substituições metonímicas que a levarão para outro lugar. Para Derrida, o inédito emerge, inelutavelmente, da repetição - o que põe em xeque oposições ingênuas como "tradição e renovação, memória e porvir, reforma e revolução" (p. 332).

Nos textos da filósofa Judith Butler, podemos verificar um movimento de interpretação e reformulação da teoria dos atos de fala que tem apresentado implicaçôes cruciais para o estudo do sujeito, do gênero e da política. A performatividade (aqui entendida, numa leitura derridiana, como o processo ou marca iterável, passível de ser repetida na ausência de seu referente, do seu significado ou de sua intenção), nos termos de Butler, é o que permite e obriga o sujeito a se constituir enquanto tal. Investindo na idéia de que o ato de fala é também um ato corporal e de que seu funcionamento se dá numa cadeia de

${ }^{3}$ De "itera", em sânscrito, o outro, e "iter", em latim, de novo. 
iterabilidade e citacionalidade, Butler defende que o sujeito reivindica sua identidade por meio de atos de fala que iteravelmente tematizam a sua própria existência.

\section{A (promessa de uma) teoria dos atos de fala}

Shoshana Felman (1980) qualifica de nietzscheano o esforço empreendido por Austin, em How to do things with words, em desmistificar a ilusão de que os fenômenos lingüísticos podem ser investigados, em sua totalidade, segundo critérios de verdadeiro e falso. De acordo com Austin, existem enunciados que não podem ser analisados a partir de uma semântica vericondicional. Trata-se dos enunciados performativos, como "eu aceito (esta mulher como minha legítima esposa)", "aposto que choverá amanhã”, que, diferentemente dos enunciados constativos, não descrevem uma situação no mundo real, de modo verdadeiro ou falso; ao contrário, eles são a realização de uma ação, que pode ser feliz ou infeliz, bem- ou malsucedida. Austin adota, portanto, condições de felicidade como critério de análise de tais enunciados. O performativo "eu aceito" será feliz se certas circunstâncias forem apropriadas, na situação concreta e convencional em que os interlocutores se engajam: sobre esse exemplo, Austin lembra que, em um país cristão, para me casar, não posso já estar casado com uma mulher "que ainda vive, que é sã e não-divorciada" (1975, p. 8-9)

Verificamos em Austin uma análise "em constante transformação, freqüentemente mais fecunda no reconhecimento dos seus impasses do que nas suas posiçôes”, conforme indica Derrida (1991, p. 363). A divisão entre enunciados constativos e performativos, proposta no início da obra, não prossegue até o fim. Numa investigação interessada, sobretudo, em indicar "os sentidos em que dizer algo é fazer algo" (p. 122), Austin põe em suspenso, em vários momentos, a distinção entre as duas classes de enunciados. $\mathrm{O}$ fato de os critérios lingüísticos estipulados por Austin na identificação de verbos performativos (primeira pessoa do presente do indicativo, voz ativa: e.g. "Eu ordeno que você saia”) não serem suficientes para dar conta das situações em

\footnotetext{
${ }^{4}$ A negação no exemplo de Austin, ao mesmo tempo em que faz rir, evidencia que o ato de fala não é imune à falha, ao tropeço e ao abuso. Nos termos de Felman (1980, p. 112), "se a capacidade para a falha é constitutiva do performativo, isso se dá porque o ato como tal é definido, em Austin, como a capacidade de errar o alvo e de falhar em sua realização".
} 
que o dizer opera um fazer (e.g. a ordem no exemplo anterior poderia ser efetuada dizendo-se "Saia daqui!") se trata de um forte indício, na argumentação "em constante transformação" de Austin, de que no lugar de uma distinção entre constativo e performativo o que se faz necessário é uma teoria que conceba a linguagem em seu caráter eminentemente performativo (Cf. FELMAN, 1980). A proposta de classificação dos atos de fala em termos de atos locucionários, atos ilocucionários e atos perlocucionários, a partir da conferência VII, surge como resposta à demanda por tal teoria (FELMAN, 1980). O ato locucionário corresponde a uma noção de significado, conforme sua definição em lógica como sentido e referência; o ato ilocucionário corresponde à força do enunciado, isto é, à ação que é realizada ao se dizer algo (e.g. informar, ordenar, prometer), considerando a situação concreta de interação; o ato perlocucionário corresponde aos efeitos produzidos por um enunciado no interlocutor, trata-se da ação realizada porque dizemos algo (e.g. persuadir, convencer, surpreender).

Podemos afirmar que o movimento de Austin é o de prometer ao leitor uma teoria, como já indiciado no próprio título da obra, How to do things with words. Queres saber como fazer coisas com palavras? Eis um manual, uma proposta, uma promessa, enfim. Trata-se de uma teoria que, ao mesmo tempo em que desconstrói uma série de crenças tradicionais, como a de que a verdade de um objeto existe independentemente do conhecimento que se tem desse objeto, se sustenta em torno da promessa, que nem sempre será cumprida:

[d] isse que tentaria alguma classificação geral preliminar e que faria algumas observações a respeito das classes [de forças ilocucionárias] propostas. Bem, então comecemos. Só levarei os leitores para uma voltinha, ou melhor, para alguns tropeçôes (AUSTIN, 1975, p. 122123, ênfase acrescida).

Como de costume, não me sobrou tempo suficiente para mostrar qual o interesse de tudo isso que acabo de dizer. Darei, porém, um exemplo. (AUSTIN, 1975, p. 131, ênfase no original).

Quanto à dimensão da promessa no trabalho de Austin, Felman aproxima os gestos teóricos de Austin à atividade sedutora de Don Juan. A linguagem para Don Juan é o domínio por excelência da sedução. E a promessa de amor donjuanesca pressupõe uma quebra em duplo sentido: ao mesmo tempo em que seu discurso amoroso leva as mulheres seduzidas por ele a romperem relacionamentos anteriores, pressupõe que a promessa de amor não 
seja cumprida. A epítome da atividade donjuanesca pode ser encontrada no dizer de Claudel (apud FELMAN, 1980, p. 57) de que "[e]sta promessa que o meu corpo te fez eu sou incapaz de cumprir". Don Juan tem na linguagem o campo do prazer; o uso que faz dela é, sobretudo, performativo: ele promete, convida, seduz... E o que se verifica em Austin, não apenas no dizer de sua teoria, mas também nos gestos de sua escrita, em sua maneira de tratar a língua, é que a linguagem tem uma dimensão eminentemente performativa (Cf. OTTONI, 1998).

Felman apresenta ainda outros desdobramentos da teoria do performativo e da promessa de uma teoria de Austin. Se, em Aristóteles, a ontologia do humano remete ao fato de o homem ser um animal político, o que evidencia uma definição de homem tendo em vista a especificidade de seus atos, em Nietzsche, o passo vai mais além: é o homem um animal prometedor. "Criar um animal que pode fazer promessas - não é esta a tarefa paradoxal que a natureza se impôs, com relação ao homem? Não é este o verdadeiro problema do homem?" (NIETZSCHE, 1998, p. 47).

Sendo a promessa um ato de fala por excelência, tem-se aqui uma posição que encara o humano não apenas especificamente a partir de seus atos, mas a partir dos atos de linguagem. A promessa e, em sentido mais amplo, a linguagem (tomada em sua dimensão performativa) indiciam a interação entre um "eu" e um "outro" num jogo em que ambos estão comprometidos, de certo modo, com as conseqüências de sua ação.

Felman direciona os questionamentos nietzscheanos à análise lingüística e à lógica: "em que medida a promessa constitui um paradoxo, um problema? De que maneira a lógica mesma da promessa é o signo de uma contradição fundamental, que é precisamente a contradição do humano?" (1980, p. 10). Segundo a autora, tais questôes, implicadas na questão do performativo, não podem ser adequadamente abordadas numa análise lingüística formal. Ao contrário, ela propõe uma análise que encontre no texto literário um ponto de articulação entre a psicanálise e o performativo, o que desemboca no "escândalo da relação incongruente mas indissociável entre a linguagem e o corpo" e também o "escândalo de um animal prometedor na medida em [sic] que este promete, justamente, o que não pode ser mantido" (p. 13, ênfases acrescidas).

Devo insistir que o escândalo da relação entre o corpo falante e o performativo interessa à teorização sobre linguagem e identidade ora empreendida. Conforme argumenta Pinto (2002), o ato de fala exige o corpo. 
$\mathrm{Na}$ cadeia em que entra o performativo, deve-se levar em conta que o ato ilocucionário (i.e., o ato que ao dizer, opera) tem sua iterabilidade também inscrita no corpo que fala.

Dito de outro modo, o ato de fala, além de participar de uma cadeia de iterabilidade, que pressupóe uma alteridade e um compromisso com o que será (e o que foi) dito, por mim e pelo outro, é também um ato corporal. Diante de tal afirmação, dois questionamentos parecem ser pertinentes. Como recuperar alteridade e compromisso em Austin? Em que sentido tais conceitos podem ser articulados com a ética bakhtiniana esboçada anteriormente? Talvez não seja o caso de "recuperar" propriamente esses dois conceitos, mas de buscar em Austin indícios para sua re-utilização. A questão da alteridade, já indicada na insistência de Austin em considerar a situação de interação, é particularmente delineada em sua reflexão sobre o uptake (traduzível por apreensão). O uptake é justamente "o reconhecimento entre os interlocutores de que algo está assegurado, de que o 'objetivo ilocucionário' foi realizado através de sua 'força”' (OTTONI, 1998, p. 81). O compromisso diz respeito ao fato de que, estando $\mathrm{o}$ ato de fala na esteira do iter (de novo), sua enunciação articula-se a uma memória, a um já-dito, e o ato de enunciá-lo me compromete com algo: "minha palavra é meu penhor", que rende dividendos para o que direi futuramente, contrariamente ou não a esse dizer, cumprindo ou não minha promessa. E também tem uma relação com o que os outros dirão, com a responsabilidade (Cf. BAKHTIN, 1993) de seus atos de fala.

E o corpo, nos termos de Pinto (2002, p. 85), como elemento indissociável da marca do ato de fala, "excede os limite do tempo de seu agir". Sua legibilidade exige tanto sua história como a possibilidade de sua repetição. Talvez postular que o corpo também esteja presente na marca iterável do ato de fala, como o fazem Butler, Felman e Pinto, seja escandaloso justamente no sentido de que isso vá de encontro a uma tradição metafísica que separa mente e corpo, linguagem e ato, constativo e performativo. Se considerarmos que o próprio sintagma ato de fala subverte a dicotomia mente/corpo ao colocar lado a lado elementos de uma oposição (a linguagem, numa visão cartesiana, diria respeito apenas à mente; o ato, ao corpo), então poderíamos afirmar que o ato de fala é, por definição, escandaloso. O corpo, como diz Lacan (apud FELMAN, 1980, p. 129), "é a fala emergindo como tal”, e é no escândalo de sua relação "incongruente mas necessária" com o ato de fala que se assentou a presente discussão sobre a identidade. 


\section{Considerações finais: performatividade e o campo aplicado}

A visão da identidade esboçada neste trabalho pode ser encarada como programática não apenas para as discussões no campo da Pragmática Lingüística, mas também da Lingüística Aplicada. A questão da performatividade, que nasce na reflexão eminentemente pragmática de John L. Austin, tem sido encarada com seriedade por uma série de autores, de campos disciplinares diversos, tendo em vista o rico potencial teórico que o conceito de performativo apresenta. Assim, Judith Butler, no campo interdisciplinar dos estudos de gênero, provocou uma verdadeira reviravolta no conceito de gênero quando, em seu livro Problemas de gênero, propôs que o gênero, ao invés de constativo, é performativo. Segundo a autora, o enunciado "É uma menina", pronunciado pelo médico quando do nascimento de uma criança, não é uma constatação, mas um enunciado performativo inicial, que irá inscrever, iteravelmente, uma feminilidade no corpo nascente (BUTLER, 2003). Para além dos estudos de gênero, poder-se-ia afirmar que todas as disciplinas que lidam com a noção de textualidade têm encarado a performatividade como uma questão central na interpretabilidade dos textos com os quais lidam. Nesse sentido, a presente reflexão pode ser encarada também como mais um gesto teórico de reivindicação da questão da performatividade para o campo aplicado.

Vale lembrar que tanto o construto teórico em questão quanto o próprio campo da Pragmática demandam um olhar interdisciplinar - marca inelutável da Lingüística Aplicada - para que se empreenda o "escrutínio desse lugar impossível”, a que me referi no início da reflexão. A presente proposta de discussão da identidade é, ao mesmo tempo, anti-essencialista e acética. Mesmo reconhecendo-se toda "instabilidade" e "impossibilidade" da identidade, temos de falar sobre ela, enxergar nela algum contorno, o que nos obriga a deixar de lado qualquer ceticismo que possa acompanhar o conceito. Trata-se, afinal, de reivindicar para a identidade algum lugar.

\section{Referências}

AUSTIN, J. How to do things with words. Cambridge: Harvard University Press, 1975.

BAKHTIN, M. Para uma filosofia do ato. Tradução não-publicada de Cristóvão Tezza. Curitiba, 1993.

BUTLER, J. Problemas de gênero. Trad. Renato Aguiar. Rio de Janeiro: Civilização Brasileira, 2003. 
BUTLER, J. Excitable speech: a politics of the performative. London and New York: Routledge, 1997.

DERRIDA, J. Assinatura acontecimento contexto. In: Margens da filosofia. Trad. Joaquim Torres Costa e Antonio M. Magalhães. Campinas: Papirus, 1991.

DERRIDA, J. Outrem é secreto porque é outro. In: Papel máquina. Trad. Evando Nascimento. São Paulo: Estação Liberdade, 2004. p. 331-358.

FAULKNER, W. Enquanto agonizo. Trad. Hélio Pólvora. Rio de Janeiro: Expansão Editorial, 1978.

FELMAN, S. Le scandale du corps parlant. Don Juan avec Austin ou la seduction em deux langues. Paris: Seuil, 1980.

FERREIRA, E. Uma reconsideração radical da noção de identidade ou a promessa de uma língua? Trabalhos de Lingüistica Aplicada, n. 40, p. 9-16, 2002. GIDDENS, A. Mundo em descontrole. Trad. Maria Luiza X. de A. Borges. Rio de Janeiro: Record, 2003.

GIDDENS, A. Modernidade e identidade. Trad. Plínio Dentzien. Rio de Janeiro: Jorge Zahar, 2002.

GIDDENS, A. As transformaçôes da intimidade: amor e erotismo nas sociedades contemporâneas. Trad. Magda Lopes. São Paulo: Ed. da Unesp, 1993.

GIDDENS, A. As conseqüências da modernidade. Trad. Raul Fiker. São Paulo: Ed. da Unesp, 1991.

GONDAR, J. Linguagem e construção de identidades - um debate. In: FERREIRA, L.; ORRICO, E. (Org.). Linguagem, identidade e memória social: novas fronteiras, novas articulações. Rio de Janeiro: DP\&A, 2002. p.107-115. HALL, S. A identidade cultural na pós-modernidade. 7. ed. Trad. Tomaz Tadeu da Silva e Guacira Lopes Louro. Rio de Janeiro: DP\&A, 2003.

HOBSBAWN, E. Introdução. In: HOBSBAWN, E.; RANGER, T. (Org.). A invenção das tradiçōes. Trad. Celina Cavalcante. Rio de Janeiro: Paz e Terra, 1997. LISPECTOR, C. A paixão segundo G. H. Rio de Janeiro: Rocco, 1998.

NIETZSCHE, F. Genealogia da moral: uma polêmica. Trad. Paulo César de Souza. São Paulo: Cia. das Letras, 1998.

OTTONI, P. Visão performativa da linguagem. Campinas: Ed. da Unicamp, 1998.

PALLARES-BURKE, M. A sociedade líquida: entrevista com Zygmunt Bauman. Folha de S. Paulo, 19 out. 2003. Caderno Mais.

PINTO, J. Estilizaçôes de gênero em discurso sobre a linguagem. 2002. Tese (Doutorado em Lingüística) - IEL, Unicamp, Campinas, 2002. Inédita. 
RAJAGOPALAN, K. Identidade e linguagem: olhares interdisciplinares. Projeto temático submetido à Fapesp. Campinas: Unicamp, 2003

RAJAGOPALAN, K. On Searle (on Austin) on language. Language and Communication, n. 20, p. 347-391, 2000.

RAJAGOPALAN, K. O conceito de identidade em linguistica: é chegada a hora de uma mudança radical? In: SIGNORINI, I. (Org.). Lingua(gem) e identidade. Trad. Almiro Pisetta. Campinas: Mercado de Letras, 1998. p. 21-45.

RAJAGOPALAN, K. Atos ilocucionários como jogos de linguagem. Estudos Lingüisticos, n. 18, p. 523-529, 1989.

SEARLE, J. Speech acts: an essay in the philosophy of language. Cambridge: Cambridge University Press, 1969.

SILVA, D. Como criar identidades com traduçôes, ou quando traduzir é intervir numa teoria. Tradução em Revista, n. 2, p. 129-145, 2005. 